\title{
MODELING AND PREDICTIVE CONTROL OF PELLET REACTORS FOR WATER SOFTENING
}

\author{
K.M. van Schagen ${ }^{*, * * 1}$ R. Babuška ${ }^{* *}$ \\ L.C. Rietveld ${ }^{* * *}$ J. Wuister ${ }^{* *}$ A.M.J. Veersma ${ }^{* * * *}$ \\ ${ }^{*}$ DHV Water B.V., P.O.Box 484, 3800 AL Amersfoort, \\ The Netherlands \\ ** Delft Center for Systems and Control, Delft University \\ of Technology, Mekelweg 2, 2628 CD Delft, The \\ Netherlands \\ *** Faculty of Civil Engineering and Geosciences, Delft \\ University of Technology, P.O.Box 5048, 2600 GA Delft, \\ The Netherlands \\ **** Amsterdam Water Supply, P.O.Box 8169, 1005 AD \\ Amsterdam, The Netherlands
}

\begin{abstract}
A nonlinear chemical/physical dynamic model in the form of partial differential equations was adopted and further developed to serve as a basis for model predictive control of a pellet reactor for drinking water softening. The model was calibrated using full-scale process measurements. A linear predictive controller based on a lineralization of the model has been designed to achieve the desired hardness of the effluent water through cost-effective operation of the reactor. This controller has been extensively validated in nonlinear simulations. The results are promising and the strategy found by the predictive controller leads to a smoother operation compared to the currently used heuristic controller.

Copyright (c) 2005 IFAC
\end{abstract}

Keywords: drinking water, softening, modeling, model predictive control

\section{INTRODUCTION}

To guarantee a high quality of drinking water, the effluent of water treatment plants (WTP) is subject to extensive monitoring. When a deterioration of the water quality is detected, the settings of the WTP are adjusted on the basis of operator knowledge and experience. The quality of drinking water is thus subject to the day-to-day decisions of individual operators.

\footnotetext{
1 Corresponding author: kim.vanschagen@dhv.nl
}

Motivated by more stringent requirements on drinking water quality and the desire to predict the water quality, more attention has recently been devoted to the research and development of new methods for the integral control of WTP. Recently, Amsterdam Water Supply, Delft University of Technology, DHV Water B.V. and ABB B.V. started a project called 'PROMICIT' (Process modeling and Integrated Control of Water Treatment). The aim is to achieve a breakthrough in drinking water quality control by developing an integral model of the total WTP and using this model as a basis for quality control. 
In this article, a new control scheme for softening reactors is described. With the current heuristic control strategy it is not possible to operate the reactors optimally. Therefore it is necessary to adopt a new control strategy.

The pellet softening is a process, which was designed in the eighties (Graveland et al. 1983, Dirken et al. 1990) and there have been a number of publications on model description and process kinetics (Harms and Robinson 1992, Tai and Hsu 2001). However, there is no known reference on using this knowledge to develop a model-based control scheme.

In this research, an existing process model (Rietveld 2004) has been adopted, modified such that it is suitable for control design and calibrated by using on-line process data. Based on a linearization of this model, a predictive controller (MPC) has been designed. This design will serve as a baseline solution for the evaluation of more advanced strategies, based on nonlinear black-box identification, adaptive control and learning.

The paper is organized as follows. In Section 2, the model equations derived from first principles are presented in a nonlinear state-space form. Section 3 addresses the calibration and validation of the model. The current control strategy is described in Section 4 and the model predictive controller in Section 5. Simulation results are discussed in Section 6 and Section 7 concludes the paper.

\section{PELLET REACTOR AND ITS MODELING}

This section describes the basic principle and the mathematical modeling of the pellet reactors at the considered WTP of the Amsterdam Water Supply company.

\subsection{Description of the pellet reactor}

Pellet reactors are cylindrical vessels filled with seeding material (garmet grains). Water is pumped through the reactor in an upward direction at relatively high speeds to maintain the grains fluidized. In the bottom of the reactor, caustic soda $(\mathrm{NaOH})$ is dosed. As a result, calcium carbonate becomes super-saturated and precipitates on the grains, which gradually turn into marble-like pellets, periodically removed from the reactor and replaced by new grains. These pellets are then reused in industry (Dijk and Wilms 1991). A schematic diagram of the reactor is shown in Fig. 1.

The aim of the softening controller is to maintain the desired calcium concentration and at the same time minimize the super-saturation of calcium

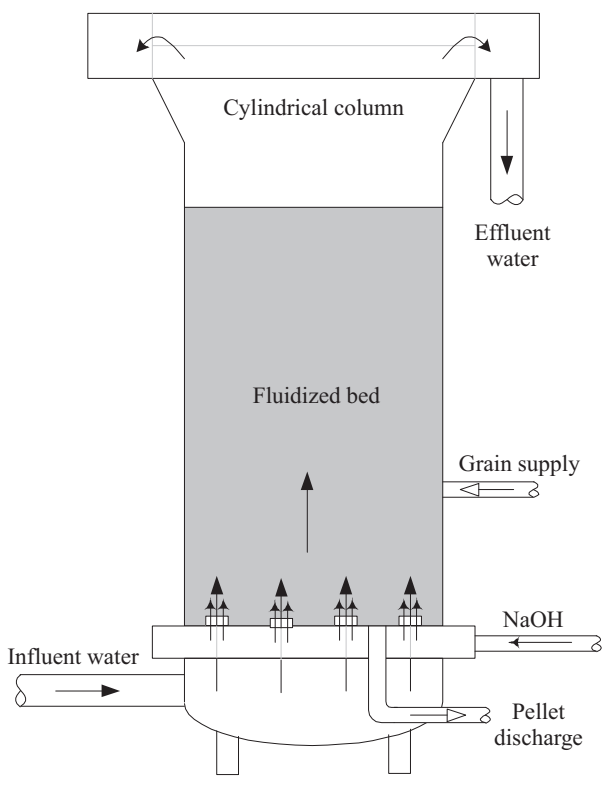

Fig. 1. Softening pellet reactor.

carbonate in order to prevent calcium carbonate deposits in the subsequent water treatment steps. The available control inputs are the water flow through the reactor, grain supply rate, pellet discharge rate and $\mathrm{NaOH}$ dosage.

At the WTP, eight reactors are operated in parallel in order to guarantee robustness and reliability of the system and to increase flexibility. To achieve higher efficiency of the softening process, the hardness is reduced more than required. Part of the water can therefore be by-passed and mixed with the effluent of the reactors.

\subsection{Mathematical modeling}

In the following, $t$ denotes time, $x$ distance from the bottom of the reactor, $[\cdot]$ concentration, $m$ mass, $\rho$ density, $d$ diameter and $F$ flow. Subscript $p$ is used for pellets, $g$ for grains (the pellet seed), $w$ for water, $c$ for calcium carbonate $\left(\mathrm{CaCO}_{3}\right)$ and $n$ for caustic soda $(\mathrm{NaOH})$. A complete list of symbols is given in the Appendix.

The model has four state variables who's dynamics and distribution in the reactor is described by:

$$
\begin{aligned}
\frac{\partial\left[\mathrm{Ca}^{2+}\right]}{\partial t} & =-\frac{F_{w}}{A p} \cdot \frac{\partial\left[\mathrm{Ca}^{2+}\right]}{\partial x}-\mathcal{C} \\
\frac{\partial M}{\partial t} & =-\frac{F_{w}}{A p} \cdot \frac{\partial M}{\partial x}-2 \mathcal{C} \\
\frac{\partial P}{\partial t} & =-\frac{F_{w}}{A p} \cdot \frac{\partial P}{\partial x}-\mathcal{C} \\
\frac{\partial m_{c}}{\partial t} & =-v_{p} L \frac{\partial \frac{m_{c}}{m_{g}}}{\partial x}+p A L M_{c} \mathcal{C}
\end{aligned}
$$

Equations (1) through (3) specify the dynamics of the $\mathrm{Ca}^{2+}$ concentration, $M$-alkalinity and $P$ alkalinity as a function of the crystallization rate 
$\mathcal{C}$, the water flow $F_{w}$ and the bed porosity $p$. Equation (4) describes how the mass of $\mathrm{CaCO}_{3}$ accumulated on the pellets depends on the crystallization rate and on the pellet discharge rate $v_{p}$ (in mass of grains per second).

In addition, the model contains an algebraic equation for the crystallization rate

$$
\mathcal{C}=k_{T} \cdot \frac{6(1-p)}{d_{p}} \cdot\left(\left[\mathrm{Ca}^{2+}\right]\left[\mathrm{CO}_{3}^{2-}\right]-K_{s}\right),
$$

where $\left[\mathrm{CO}_{3}^{2-}\right]$ is found by solving the following equations for the carbonic acid equilibrium (Stumm and Morgan 1996):

$$
\begin{aligned}
M & =2\left[\mathrm{CO}_{3}^{2-}\right]+\left[\mathrm{HCO}_{3}^{-}\right]+\left[\mathrm{OH}^{-}\right]-\left[\mathrm{H}_{3}^{+} \mathrm{O}\right] \\
P & =\left[\mathrm{CO}_{3}^{2-}\right]-\left[\mathrm{CO}_{2}\right]+\left[\mathrm{OH}^{-}\right]-\left[\mathrm{H}_{3}^{+} \mathrm{O}\right] \\
K_{1} & =\left[\mathrm{HCO}_{3}^{-}\right]\left[\mathrm{H}_{3}^{+} \mathrm{O}\right]\left[\mathrm{CO}_{2}\right]^{-1} \\
K_{2} & =\left[\mathrm{CO}_{3}^{2-}\right]\left[\mathrm{H}_{3}^{+} \mathrm{O}\right]\left[\mathrm{HCO}_{3}^{-}\right]^{-1} \\
K_{w} & =\left[\mathrm{H}_{3}^{+} \mathrm{O}\right]\left[\mathrm{OH}^{-}\right]
\end{aligned}
$$

with $K_{1}, K_{2}, K_{w}$ being known (temperaturedependent) constants. The bed porosity $p$ is derived from the equation of Carman-Kozeny (Bird et al. 1960, Montgomery 1985):

$$
\frac{p^{3}}{(1-p)^{C_{e}}}=C_{c} \frac{v^{2-C_{e}}}{g} \frac{\nu^{C_{e}}}{d_{p}^{1+C_{e}}} \frac{\rho_{w}}{\rho_{p}-\rho_{w}} .
$$

The pellet diameter $d_{p}$ is calculated by distributing the accumulated mass $m_{c}$ evenly over the available (spherical) grains:

$$
d_{p}=d_{g} \sqrt[3]{1+\frac{m_{c}}{m_{g}} \frac{\rho_{g}}{\rho_{c}}}
$$

which also gives the pellet density:

$$
\rho_{p}=\left(m_{c}+m_{g}\right)\left(\frac{m_{c}}{\rho_{c}}+\frac{m_{g}}{\rho_{g}}\right)^{-1} .
$$

For control purposes, additional outputs are used. An important indicator for monitoring the water quality is the saturation index, defined as the difference between the actual $\mathrm{pH}$ and the $\mathrm{pH}$ at which $\left[\mathrm{CO}_{3}^{2-}\right]$ equals $K_{s} /\left[\mathrm{Ca}^{2+}\right]$, as a solution of the equilibrium equations (6):

$$
\mathrm{SI}=\log \left(\left[\mathrm{Ca}^{2+}\right]\left[\mathrm{CO}_{3}^{2-}\right] \frac{1}{K_{s}}\right)
$$

where $K_{s}$ is the solubility product (a temperaturedependent constant). The pressure drop over the fluidized bed is also measured. In the model, it is given by the submerged weight of the pellets:

$$
\Delta P=\left(\rho_{p}-\rho_{w}\right)(1-p) L g
$$

where $L$ is the bed height:

$$
L=\frac{m_{p}}{\rho_{p}(1-p) A} .
$$

Finally, the effluent water $\mathrm{pH}\left(-\log \left(\left[\mathrm{H}_{3}^{+} \mathrm{O}\right]\right)\right.$ is also measured.

\subsection{Model simulation}

The equations presented in Section 2.2 are nonlinear and can only be solved numerically. The flow pattern in the reactor is approximated as a onedimensional flow, assuming several completely mixed compartments in series. In each compartment, the change of calcium concentration, calcium carbonate accumulation, M-alkalinity and P-alkalinity can be calculated in time by solving the discretized ordinary differential equations simultaneously. The model is implemented as a state-space model in MATLAB/Simulink with the following inputs, states and outputs:

$$
\begin{aligned}
& \mathbf{u}=\left[\begin{array}{lll}
F_{w} & F_{n} & v_{p}
\end{array}\right]^{T} \\
& \mathbf{x}=\left[\begin{array}{lllll}
\mathrm{Ca}_{1}^{2+} & M_{1} & P_{1} & m_{s, 1} & \mathrm{Ca}_{2}^{2+}
\end{array} \ldots\right. \\
& \left.\mathrm{Ca}_{n}^{2+} M_{n} P_{n} m_{s, n}\right]^{T} \\
& \mathbf{y}=\left[\begin{array}{lllll}
\mathrm{Ca}_{n}^{2+} & \mathrm{pH} \Delta P & L & d_{p, 1} & \mathrm{SI}_{n}
\end{array}\right]^{T}
\end{aligned}
$$

The number of compartments $n$ is determined by examining the hydraulic retention time of the reactor. In our case, the reactor is modeled by using 10 compartments.

\section{MODEL CALIBRATION}

The model has been calibrated by using process data of the WTP. The goal is to minimize the difference between the measured data $\left(\mathbf{y}_{m}\right)$ and simulated data $\left(\mathbf{y}_{s}\right)$. As the measurements are taken with different sampling periods (varying from a minute to one week), the cost for each measurement is normalized by the number of available samples $N_{m}$ :

$$
\mathrm{MSE}=\sum_{i=1}^{6} \frac{1}{N_{m, i}} \sum_{k=1}^{N_{m, i}}\left(\frac{y_{s, i}(k)-y_{m, i}(k)}{y_{m, i}(k)}\right)^{2}
$$

The first sum is the summation for all outputs, see also (15), and $k$ denotes discrete time index. For two periods (summer and winter), five parameters (Table 1 ) in the model were calibrated by fitting simulation data to the data of eight independent reactors in the plant. The initial state of each run was estimated by calculating the steady-state using the average inputs for the calibrated period and the modified parameters. Using this initial condition a simulation of a two week period was performed.

Data from reactors $1,2,4,6,8$ were used for the summer period and from reactors $3,4,6,7,8$ for 
Table 1. Parameters to be calibrated and their range.

\begin{tabular}{llrr}
\hline Parameter & & Min & Max \\
\hline Mass of grains & $\mathrm{m}_{g}$ & 100 & 4400 \\
Reaction rate & $\mathrm{k}_{T}$ & 0.001 & 0.050 \\
Drag constant & $\mathrm{C}_{c}$ & 0 & 260 \\
Drag coefficient & $\mathrm{C}_{e}$ & 0 & 1 \\
\hline
\end{tabular}

the winter period. Data from the remaining reactors could not be used due to the maintenance of a reactor, malfunction of sensors or missing laboratory results. The $\mathrm{pH}$, flow, temperature, hardness and pressure drop are measured every minute, while calcium, bicarbonate, super saturation, pellet diameter, bed height are measured at longer intervals (daily to weekly). Note that the distribution of the state variables over the height of the reactor cannot be measured on the process.

Table 2. Parameters and MSE (Summer).

\begin{tabular}{rrrrrr}
\hline No. & $m_{g}$ & $k_{T}$ & $C_{c}$ & $C_{e}$ & $\mathrm{MSE}$ \\
\hline 1 & 799 & 0.0194 & 177 & 0.65 & 0.041 \\
2 & 2175 & 0.0154 & 152 & 0.72 & 0.030 \\
4 & 1839 & 0.0200 & 153 & 0.69 & 0.065 \\
6 & 1830 & 0.0183 & 156 & 0.71 & 0.035 \\
8 & 3676 & 0.0133 & 144 & 0.74 & 0.087 \\
mean & $\mathbf{2 0 6 4}$ & $\mathbf{0 . 0 1 7 3}$ & $\mathbf{1 5 6}$ & $\mathbf{0 . 7 0}$ & $\mathbf{0 . 0 5 2}$ \\
$\sigma$ & $50 \%$ & $16 \%$ & $8 \%$ & $5 \%$ & $46 \%$ \\
\hline
\end{tabular}

Table 3. Parameters and MSE (Winter).

\begin{tabular}{rrrrrr}
\hline No. & $m_{g}$ & $k_{T}$ & $C_{c}$ & $C_{e}$ & $\mathrm{MSE}$ \\
\hline 3 & 955 & 0.0100 & 154 & 0.66 & 0.024 \\
4 & 2006 & 0.0066 & 145 & 0.69 & 0.018 \\
6 & 3200 & 0.0083 & 156 & 0.75 & 0.085 \\
7 & 2220 & 0.0079 & 133 & 0.68 & 0.026 \\
8 & 1261 & 0.0094 & 139 & 0.71 & 0.023 \\
mean & $\mathbf{1 9 2 8}$ & $\mathbf{0 . 0 0 8 4}$ & $\mathbf{1 4 6}$ & $\mathbf{0 . 7 0}$ & $\mathbf{0 . 0 3 5}$ \\
$\sigma$ & $46 \%$ & $15 \%$ & $7 \%$ & $5 \%$ & $79 \%$ \\
\hline
\end{tabular}

The calibration results are given in Tables 2 and 3. One can see that the mass of grains considerably differs from reactors to reactor, which indicates that the reactors are in different states. The remaining parameters are within a reasonable range. The comparison between summer and winter reveals the temperature-dependent reaction rate $k_{T}$ (as expected).

\section{CURRENT CONTROL STRATEGY}

The eight parallel reactors are currently operated at constant and equal setpoints. Depending on the temperature, operators manually change the bypass ratio. There are four controllers that regulate the softening process (Figure 2).

(1) The bypass controller is responsible for maintaining the manually set bypass ratio.

(2) The flow distribution controller distributes the total flow equally over the reactors.
(3) The caustic soda controller regulates the $\mathrm{NaOH}$ dose to achieve the desired hardness of the mixed effluent of $1.5 \mathrm{mmol} / \mathrm{l}$. The setpoint the $\mathrm{NaOH}$ dose is calculated by using an empirical formula based on the bypass ratio, the water flow, the effluent $\mathrm{pH}$ and a manual correction.

(4) The pellet discharge controller in an on-off controller that keeps the total pressure drop over the reactor between 16.5 and $17.2 \mathrm{kPa}$ in order to limit the bed height (which is not directly measured).

In summer, this operation practice results in a higher bypass ratio and higher $\mathrm{NaOH}$ dosages. In winter, hardly any bypass will be applied and the $\mathrm{NaOH}$ dosages are lower. To be able to keep the saturation index at acceptable levels, the maximum pellet size is decreased in winter in order to increase the crystallization surface. In summer the opposite happens.

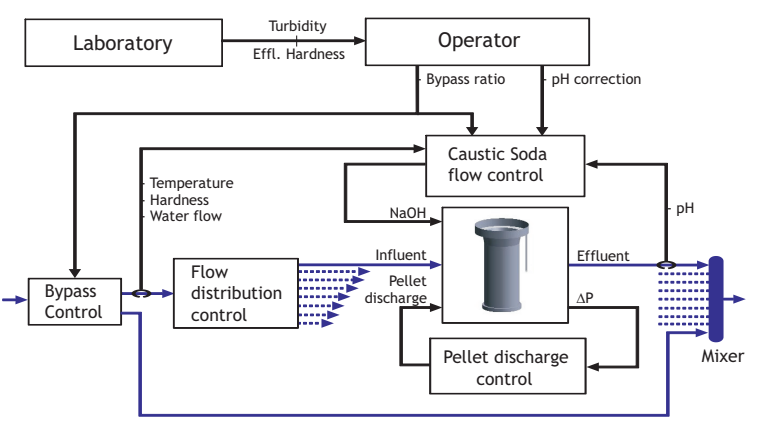

Fig. 2. Current control loops.

\section{MODEL PREDICTIVE CONTROL}

With the current heuristic control strategy it is not possible to operate the system optimally. Therefore it is necessary to adopt a new control strategy, which can take into account qualityrelated and economic criteria and optimize the overall performance of the bank of parallel reactors. A two-level control architecture is proposed:

Local model predictive controllers (Camacho and Bordons 1995) control the individual reactors. They manipulate the caustic soda flow, water flow and pellet discharge rate, while explicitly respecting the physical constraints of the reactor and additional constraints to guarantee smooth changes of the control signals.

A supervisory controller determines set-points and model and control parameters for the local controllers. Its task is to find the optimal distribution of the water flow over the reactors and bypass channels and the desired effluent hardness for each reactor, while minimizing the super saturation and the total operational costs. Eventually, the supervisory controller should also determine 
whether reactors can be switched off (for economic or maintenance reasons) or whether additional reactors should be switched on (e.g., in peakload situations). A secondary goal may be the control of the pellet properties (such as size) in the individual reactors.

In this paper we focus on the MPC for a single pellet reactor. The controller model is obtained through numerical lineralization of the complex nonlinear model of Section 3. The control objectives are to follow the set-points of the supervisory controller under smooth variation of the manipulated inputs, as formulated in the following objective function:

$$
\begin{aligned}
J= & \sum_{j=N_{m}}^{N}\left\|\mathbf{y}(k+j \mid k)-\mathbf{r}_{y}(k+j)\right\|_{P}^{2} \\
& +\sum_{j=1}^{N}\|\Delta \mathbf{u}(k+j \mid k)\|_{Q_{\Delta u}}^{2} \\
& +\sum_{j=1}^{N}\left\|\mathbf{u}(k+j \mid k)-\mathbf{r}_{u}(k+j)\right\|_{Q_{u}}^{2}
\end{aligned}
$$

where $N$ and $N_{m}$ are the prediction horizon and the minimum cost horizon, and $\mathbf{r}_{u}$ and $\mathbf{r}_{y}$ are the references for the inputs and the outputs.

\section{RESULTS AND DISCUSSION}

To evaluate the performance of the controller, simulations were performed for the summer period, with varying reference signals for calcium concentration and water flow. The reference for the saturation index is zero. The parameters of the nonlinear model used for the controller model are the mean parameters given in Table 2. The operating point for the linearized model is the steady-state of the nonlinear model with the average influent flow, dosing and pellet discharge of the calibrated reactors. The weighting matrices in (17) are diagonal, given by:

$$
\begin{aligned}
P & =\operatorname{diag}\left(\left[\begin{array}{llllll}
3 & 0 & 0 & 0 & 0 & 2
\end{array}\right]\right) \\
Q_{u} & =\operatorname{diag}\left(\left[\begin{array}{lll}
1 & 0 & 0
\end{array}\right]\right) \\
Q_{\Delta u} & =\operatorname{diag}\left(\left[\begin{array}{lll}
1 & 5 & 2
\end{array}\right]\right)
\end{aligned}
$$

The non-zero weights in $P$ and $Q_{u}$ penalize the deviation of the Calcium concentration, Saturation Index and water flow from their reference values, see also (13) and (15). Change in the manipulated variables are penalized to get a smooth transition between operation points. In addition, level constraints are defined for all outputs and inputs, based on their physical ranges. To make the simulation more realistic, noise was added to the simulated outputs.

The simulation results using the nonlinear process model of Reactor 4 are shown in Figures 3 and 4 .
The reference signal for the flow was $350 \mathrm{~m}^{3} / \mathrm{h}$ with a step to $400 \mathrm{~m}^{3} / \mathrm{h}$ after $55 \mathrm{~min}$. for the Calcium concentration, a reference of $40 \mathrm{mg} / \mathrm{l}$ with a step to $30 \mathrm{mg} / \mathrm{l}$ was used.
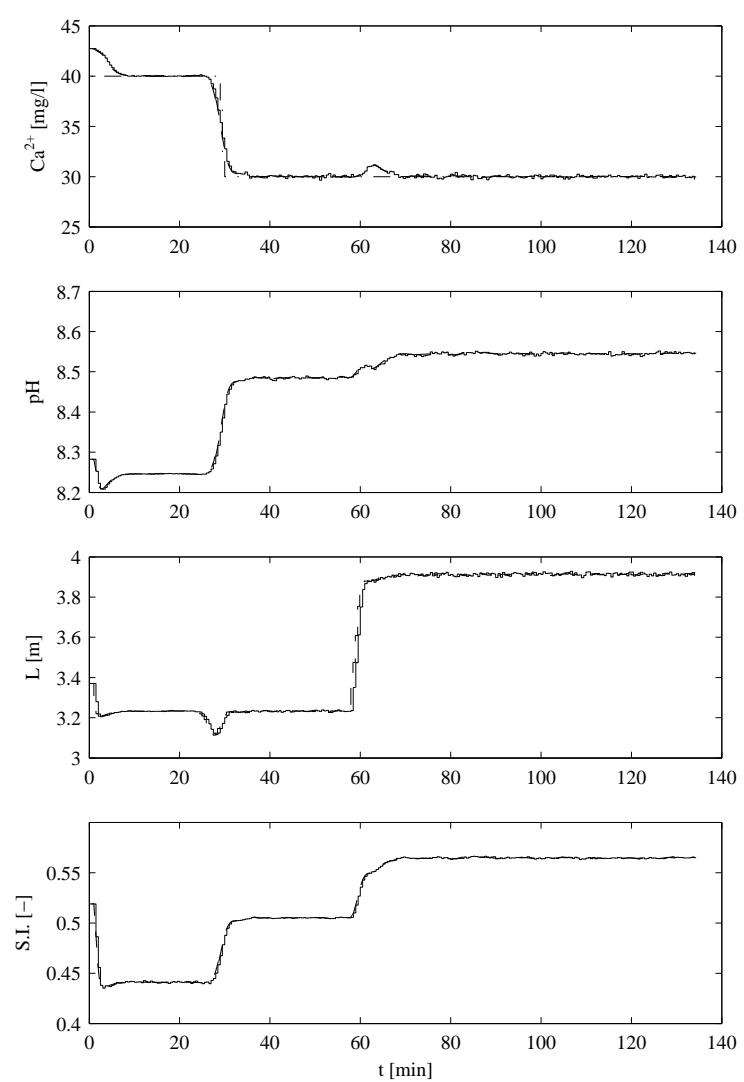

Fig. 3. Simulation results outputs. dashed-dot : Reference, dashed : Estimate, solid : Process.
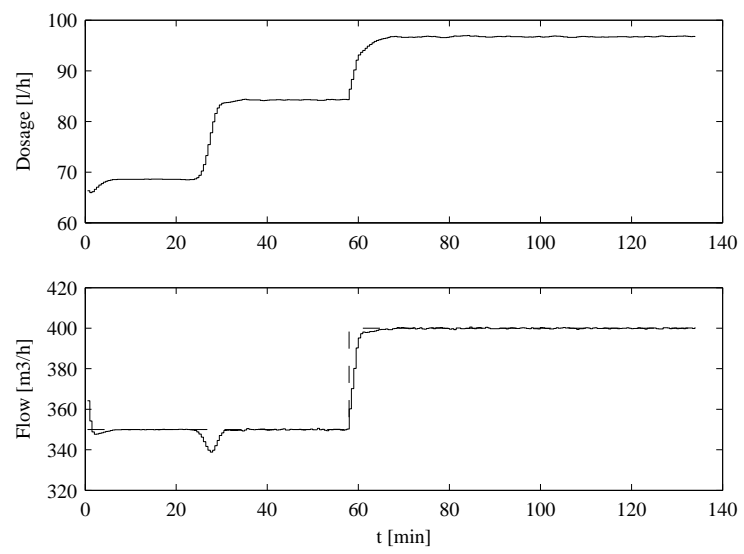

Fig. 4. Simulation results control inputs. dashed : Reference, solid : MPC.

It can be seen, that the tracking of the reference signal is appropriate, including the desired smooth transition. Notice that in order to track the calcium reference, the MPC automatically lowered the flow to the reactor after 30 minutes. Another interesting observation is that the water flow through the reactor and the $\mathrm{NaOH}$ dosage are not strictly linked (as opposed to the current 
heuristic strategy). A flow reference change shows a rapid flow response, but a relatively slow dosage response, which results in a negligible change of the Saturation Index.

\section{CONCLUSIONS AND FUTURE RESEARCH}

A new control scheme for softening pellet reactors has been proposed to replace the current heuristic control strategy. A white-box process model has been successfully calibrated and used in modelpredictive control. Simulations show that MPC has a good potential for controlling the pellet reactor, by explicitly taking into account quality and economic control objectives and constraints. The most significant difference from the current control strategy is the multi-variable character of the controller and the smoothness of the control actions, which required from the practical operation viewpoint.

This design will serve as a baseline solution for the evaluation of more advanced strategies, based on nonlinear black-box identification, adaptive control and learning. From December 2004 the first results of the implementation of the developed control scheme on a pilot plant will be available. Our future research will focus on the development of the supervisory controller and a suitable method for dealing with significant time delays and multi-rate sampling in the measurements.

\section{ACKNOWLEDGEMENT}

The PROMICIT project is sponsored by Senter, Ministry of Economic Affairs of the Netherlands.

\section{Appendix A. LIST OF SYMBOLS}

\section{Input variables:}

\begin{tabular}{lll}
\hline$F_{w}$ water flow through reactor & $\mathrm{m}^{3} \mathrm{~s}^{-1}$ \\
$F_{n}$ caustic soda flow & $\mathrm{m}^{3} \mathrm{~s}^{-1}$ \\
$v_{p} \quad$ pellet discharge rate & $\mathrm{kg} \mathrm{s}^{-1}$ \\
\hline
\end{tabular}

\section{State variables:}

\begin{tabular}{lll}
\hline$\left[\mathrm{Ca}^{2+}\right]$ & concentration of $\mathrm{Ca}^{2+}$ & $\mathrm{mmol} / 1$ \\
$M$ & m-alkalinity & $\mathrm{mmol} / 1$ \\
$P$ & p-alkalinity & $\mathrm{mmol} / 1$ \\
$m_{c}$ & accumulated mass of $\mathrm{CaCO}_{3}$ & $\mathrm{~kg}$ \\
\hline
\end{tabular}

\section{Other variables:}

\begin{tabular}{lll}
\hline $\mathcal{C}$ & crystallization rate & $\mathrm{mmol} \mathrm{l}^{-1} \mathrm{~s}^{-1}$ \\
$d_{p}$ & pellet diameter & $\mathrm{m}$ \\
$L$ & bed height & $m$ \\
$p$ & bed porosity & - \\
$\mathrm{pH}$ & $\mathrm{pH}$ value & - \\
$\mathrm{SI}$ & saturation index & - \\
$\Delta P$ & pressure drop over the bed & $\mathrm{Pa}$ \\
\hline
\end{tabular}

\section{Parameters:}

\begin{tabular}{lll}
\hline$A$ & reactor area & $\mathrm{m}^{2}$ \\
$K_{s}$ & solubility product & $\mathrm{mmol}^{2} / \mathrm{l}^{2}$ \\
$K_{1,2}$ & equilibrium constants & $\mathrm{mmol} / \mathrm{l}$ \\
$K_{w}$ & equilibrium constant & $\mathrm{mmol}^{2} / \mathrm{l}^{2}$ \\
$k_{T}$ & reaction rate & $1 \mathrm{~m} \mathrm{~s}^{-1} \mathrm{mmol}^{-1}$ \\
$M_{c}$ & CaCO $_{3}$ molecular weight & $\mathrm{g} / \mathrm{mmol}^{2}$ \\
$\rho_{c}$ & density of CaCO 3 & $\mathrm{~kg} / \mathrm{m}^{3}$ \\
$d_{g}$ & grain diameter & $\mathrm{m}$ \\
$m_{g}$ & mass of grains & $\mathrm{kg}$ \\
$\rho_{g}$ & grain material density & $\mathrm{kg} / \mathrm{m}^{3}$ \\
$\nu$ & viscosity of water & $\mathrm{m}{ }^{2} / \mathrm{s}$ \\
$g$ & gravity constant & $\mathrm{m} / \mathrm{s}^{2}$ \\
$C_{c}$ & drag constant & - \\
$C_{e}$ & drag exponent & - \\
$\rho_{w}$ & density of water & $\mathrm{kg} / \mathrm{m}^{3}$ \\
\hline
\end{tabular}

\section{REFERENCES}

Bird, R.B., W.E. Stewart and E.N. Lightfoot (1960). Transport Phenomena. Wiley, New York.

Camacho, E.F. and C. Bordons (1995). Model Predictive Control. Springer, New York.

Dijk, J.C. van and D. Wilms (1991). Water treatment without waste material - fundamentals and state of the art of pellet softening. Journal of Water Supply:Research and Technology-AQUA Vol 40(5), 263-280.

Dirken, P., E. Baars, A.Graveland and F.C. Woensdregt (1990). In: Industrial Crystallization 90 (A. Mersmann, Ed.). Elsevier. Garmisch Partenkirchen, Germany. pp. 95100.

Graveland, A., J.C. van Dijk, P.J. de Moel and H.H.C.M. Oomen (1983). Developments in water softening by means of pellet reactors. J. $A W W A$ 75(12), 619-625.

Harms, Willard D. and R. Bruce Robinson (1992). Softening by fluidized bed crystallizers. Journal of enviromental engineering 118(4), 513529.

Montgomery, J.M. (1985). Water treatment, Principles \& Design. John Wiley \& Sons, New York, USA.

Rietveld, L.C. (2004). Improving operation of drinkingwater treatment through modeling. PhD thesis. Faculty of Civil Engineering and Geosciences, Delft University of Technology.

Stumm, Werner and James J. Morgan (1996). Aquatic chemistry: chemical equilibria and rates in natural waters. John Wiley \& Sons, New York, USA.

Tai, Clifford Y. and Hsiao-Ping Hsu (2001). Crystal growth kinetics of calcite and its comparison with readily soluble salts. Powder Technology 121, 60-67. 